presentación al Ministerio de Justicia, del cual hay varias evidencias significativas: ha sido publicado de inmediato en soporte papel, los centros académicos más respetados realizan jornadas de estudio y de análisis en todo el país $\left(^{* *}\right)$, y en las revistas especializadas ya aparecen los primeros comentarios de los juristas.

El mayor entusiasmo proviene de los más jóvenes, para quienes resulta intolerable que continúen siendo operativas normas que fueron adecuadas para el siglo XIX, pero que son incompatibles con la reforma constitucional de 1994, con los tratados dotados de jerarquía constitucional conforme al inciso 22 de su artículo 75 , y con las exigencias de la economía de mercado. Hiere la racionalidad que el Código de Comercio ponga todavía el acento en la responsabilidad resultante del transporte en "falúas" y en "canoas" (artículo 206); que el sistema se ocupe del agente (artículo 1151, Código Civil), quien habría viajado a caballo o en barco, y de la celebración del contrato por correspondencia (nota a los artículos 1150 a 1154, Código Civil); y que el Código Civil no mencione a las máquinas ni en el texto ni en las notas del Título en el que trata de los hechos ilícitos. El Código de Comercio alude al mensajero (artículo 215), y asume como novedad tecnológica a la correspondencia telegráfica (artículo 214; el telégrafo había sido patentado en 1840 ), porque lo normal

(*) El Proyecto argentino ya ha despertado interés en el plano académico internacional. En el antes mencionado Seminario se ocuparon de analizarlo los profesores italianos de la Università di Roma La Sapienza doctores Pietro Rescigno y C Massimo Bianca; de la Università di Roma Tor Vergata, doctores Sandro Schipani y Paolo Papant Pelletier; de L Scuola Superiore Santa Anna di Pisa, doctor Francesco Donato Busnelli; y el profesor brasileño de la Universidade de Sâo Paulo doctor Alvaro Villaç Azevedo. En Perú, será analizado en la Universidad Nacional San Martín de Arequipa, en el marco del II Congreso Nainaç Derecho Civil de Arequipa (4 al 6 de agosto de 1999).

en el sistema era comunicarse mediante el correo (artículo 246), lo cual podía determinar que hubiera demoras notables en la trasmisión de la manifestación de la voluntad (artículo 236)...

Todo ello es congruente con la época de sanción del Código Civil: en 1869 no habían luz eléctrica, teléfonos, fonógrafos, linotipia, lapiceras fuente, automóviles propulsados a nafta o a diesel, neumáticos de caucho, películas flexibles para fotografía, cine, submarinos; no se cultivaban bacterias; no se conocía la causa de la tuberculosis ni la del tétanos, ni los rayos $\mathrm{X}$, ni los virus filtrables; no había sido fundado el psicoanálisis, ni se había descubierto la radiación del átomo de uranio.

Pero, evidentemente, las cosas han cambiado de $\mathrm{m}$ odo radical, primero por el auge de la sociedad industrial que los viejos Códigos no tomaron en cuenta y, en la segunda mitad de este siglo, por la irrupción de la era postindustrial o tecnológica, así como por el reciente -pero avasallador fenómeno de la globalización.

10. Argentina está en situación de tener un Código Civil moderno, a compás de los tiempos actuales, que sea -además el primero del siglo XXI.

Ello depende, claro está, de la opinión que le merezca el Proyecto a la comunidad jurídica, y -en su caso- de la decisión política gubernamental de sancionarlo.

Revista da Faculdade de Direito da UFRGS, v. 17, 1999

\section{A Função de Satisfação na Indenização do Dano Pessoal Um elemento penal na satisfação do dano ?*}

\author{
Privatdorent Dx. Bexnd- Rïdigex OKexn \\ Tradução de Lélio Candiota de Campos
}

\section{Introdução}

art. 847 do BGB (Código Civil Alemão)** assegura uma indenização eqüitativa em dinheiro para determinados danos não patrimoniais. A este respeito, desde a decisão do Grande Senado (Gross Senat) do ano de $1955^{1}$ e de acordo com jurisprudência uniforme e a doutrina dominante, entende-se que não se trata de pretensão comum de indenização por perdas e danos, mas de uma "pretensão de na- tureza peculiar, com dupla função: propiciar ao lesado uma compensação adequada" à injustiça que sofreu e "ao mesmo tempo levar em conta que o autor do dano deve ao ofendido uma satisfação pelo que lhe fez". ${ }^{2}$ Quanto a isso, a revogação da segunda parte da alínea primeira do art. $847 \mathrm{em}$ $01.07 .1990^{3}$ nada mudou. O dossiê desta lei refere que "as pretensões de dano pessoal servem à compensação do dano e à satisfação da vítima". ${ }^{4}$
- Versão, ampliada e com anotaçōes, da habilitação proferida em 28 de Junho 1988 na Faculdade de Direito da Eberhard-KarlsUniversität, Tübingen. Os §§§ sem caracterizaçãa são os do BGB. Art. publicado no Archiv für die civilistische Praxis, vol. 191, ano 1991, pp. 247/272, Tübingen, Alemanha, traduzido pelo Prof. Lélio Candiota de Campos, com autorizaçăo do autor. O tradutor agradece a eficiente colaboração da Profa $D r^{a}$ Cláudia Lima Marques, que gentilmente revisou esta traduçáo, bem como do mestrando Christoph Fabian pela tradução das notas de rodapé.

** N.T. - Texto do art. 847 do BGB: (Dano nåo Patrimonial) No caso de lesão do corpo ou da saúde, assim como no caso de privaçắo de liberdade, pode o lesado, também por causa do dano não patrimonial, exigir uma eqüitativa satisfaçãa em dinheiro. A preten-
são não e transmissivel e nấo passa para os herdeiros, salvo se tiver sido reconhecida por contrato ou tornado-se litispendente. A mesma pretensão cabe à mulher contra a qual foi cometido crime ou contravençăo contra os bons costumes, ou que foi levada, por astúcia, ameaça ou abuso de relação de dependência, a consentir em coabitação extramatrimonial.

1. BGHZ 18, 149.168; sobre isto amplamente critico Schiemann, Argumente und Prinzipien bei der Fortbildung des Schadensrechts, dargestellt an der Rechtsprechung des BGH, 1981, pp. 8-12.

2. Ementa do Supremo Tribunal Federal (BGH), BGHZ 18, 149.

3. Art. $1^{2}$ da Lei de Alteração do Bürgerliches Gesetzbuch e outras leis, de 14.3.1990; BGBI. I, 478. Cf. sobre isto Hammsen, Zur geplanten Streichung von $\$ 847$ I S.2 BGB, em: VersR 1989, 1121-1123: e U.VoB, Vererblichkeit und Übertragbarkeit des Schmerzensgeldanspruchs, em: VersR 1990, 821-826.

4. Relatos dos deputados Dr. Hüsch und Stiegler de 19. Outubro 1989: BT-Dr. 11/5423.

Revista da Faculdade de Direito da UFRGS, v. 17, 1999 
A função de compensação deve reparar tanto as dores sofridas como a perda da alegria de viver. Ao ofendido têm de ser "oferecidas vantagens de outra natureza por seu prejuízo imaterial". Não cabe, porém, pensar em compensação em sentido estrito, ${ }^{5}$ porque falta um denominador comum ao dano imaterial e à compensação pecuniária. "Pois o dano imaterial (...) tal como a expiação, não pode ser calculado

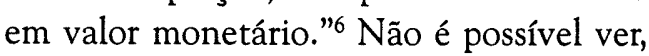
demonstrar ou calcular o dano imaterial, mas somente senti-lo. ${ }^{7}$ Tomando-se os padrões habituais de indenização, chega-se à compensação, a qual, no entanto, a final só poderá ser "compensação simbólica"8 ou em sentido figurado. Por tais motivos, a função de satisfação é adicionada à compensação, complementa-a em diferentes medidas. ${ }^{9}$ "Ela expressa uma determinada relação pessoal que o fato danoso suscita entre o ofensor e o ofendido, a qual, por sua natureza, exige que na determinação do montante devido sejam levadas em consideração todas as circunstâncias do caso."10

A questão de saber qual a finalidade que a função de satisfação tem de cumprir, o que ela significa, é discutível. Mencionamse no máximo três finalidades: ${ }^{11}$ de um lado, deve trazer ao lesado um sentimento de satisfação, apaziguar seu senso de justiça ferido; de outro, deve impor ao ofensor um sensível sacrifício patrimonial; e, por último, com isso deve atuar preventivamente no futuro. ${ }^{12}$

Ambas as funções impõem que diversos fatores sejam levados em consideração. A função de compensação exige que se leve em conta a importância, a medida e a duração do dano. Ter-se-á que considerar até a intensidade e a duração das dores físicas, os cuidados durante a convalescença relacionados com o fato danoso e o enfraquecimento da vontade de viver decorrente de incapacidades e deformações permanentes. ${ }^{13}$ Para a idéia de satisfação é da maior importância o grau de culpa. ${ }^{14}$ "O grau de culpa deve ser considerado não apenas (...) com vista à reação que provoca no lesado. Com efeito, a circunstância de o

5. A Adéia de compensação no sentido estrito não ajuda nos casos em que são adjudicadas [pelo tribunal] indenizações em dinheiro, embora seja duvidoso se de todo existe um dano quantificável em dinheiro. Isto vale também para todos os casos do assim chamado dano normativo. Cf. sobre isto Meder, Schadensersatz als Enttäuschungsverarbeitung, 1989, pp. 132 e sg., 148 e sg.; e Herm. Lange, Handbuch des Schuldrechts, Bd. 1, Schadensersatz, 2. ed., 1990, pp. 54-58.

6. K. Larenz, Lehrbuch des Schuldrechts, Bd.1, Allgemeiner Teil, 14. ed., 1987, § 28 III, p. 475.

7. Pecher, crítica da obra de E. Lorenz, Immaterieller Schaden und "billige Entschädigung in Geld", em: AcP 185 (1985), 383-396, 385.

8. Meder, p. 148.

9. Assim também Herm. Lange, pp. $435 \mathrm{sg}$

10. BGHZ 18, 149, 157.

11. Deutsch, Haftungsrecht, Bd.1, Allgemeine Lehren, 1976, p. 473.

12. Assim também Herm. Lange, p. 438. Sobre a função preventiva cf. mais Deutsch, Haftungsrecht, p. 474: W.H. Eberbach, Die zivilrechtliche Beurteilung der Humanforschung, 1982, pp. 138, 145, 154: e Motsch, Schadensersatz als Erziehungsmittel, JZ 1984, 211-221.

13. Cf. a apresentação detalhada de Hupfer, Schmerzensgeld bei Verkehrsunfallopfern, JZ 1977, 781-785, 782

14. Herm. Lange, 1. ed. 1979, p. 267.

Revista da Faculdade de Direito da UFRGS, v. 17, 1999 dano provir de culpa grave ou até mesmo de um comportamento doloso do ofensor certamente pode deixar a vítima cheia de amargura, ao passo que quando o dano é causado por um leve descuido o lesado tende antes a aceitar o fato como fatalidade do destino. Mas, abstraindo inteiramente a reação da vítima, isso pode estar em conformidade com a eqüidade e a idéia de satisfação se, no caso concreto, a intencionalidade ou a culpa grave foi levada em consideração para estabelecer a indenização do art. 847 em desfavor do autor do dano, ou então, ao contrário, em seu favor quando a culpa é leve (sic!). Seria incompreensível que o juiz do fato não tivesse atribuição para estimar o efeito da dor causada por um criminoso em valor mais elevado que as mesmas conseqüências exteriores de um comportamento faltoso no trânsito, possível de acontecer a qualquer um. ${ }^{15}$ Com isto, na compensação dos danos imateriais o $\mathrm{BGB}^{16}$ conscientemente desconsidera o princípio básico vigente no direito alemão em matéria de danos patrimoniais e expressado no "tudo ou nada", de acordo com o qual o mais ínfimo

grau de culpa tem por resultado a mesma prestação indenizatória do dolo. ${ }^{17}$ Mas também outros aspectos podem ter relevância: as circunstâncias do fato, ${ }^{18}$ as relações econômicas entre o ofensor ${ }^{19}$ e o ofendido, 20 circunstâncias paralelas à evolução ${ }^{21} \mathrm{e}-$ muito discutido 22 - a pena criminal imposta. ${ }^{23}$ Não é possível estabelecer uma ordem de prioridades nessas situações. Nem são sempre todas consideradas. Conforme 0 caso, devem ser postas de lado. ${ }^{24}$ Com isso em mente, devem ser avaliadas e somadas as funções de compensação e de satisfação, mas nunca como se fossem parcelas independentes. Ao contrário, trata-se "de duas maneiras de atuar da mesma pretensão, não necessariamente em seus pormenores, e que se completam reciprocamente dentro de uma delimitação". ${ }^{25}$ Num exame conjunto, elas fluem sob a óptica da eqüidade.

A jurisprudência do $\mathrm{BGH}$ (Bundesgerichtshof - Supremo Tribunal Federal), à qual os tribunais de instância (Instanzgerichte) aderiram praticamente sem exceção, encontrou em seguida oposição na literatura jurídica, cuja crítica perdura ain-

15. $B G H Z 18,149,157$ e sg

16. BGHZ 18, 149, 158.

17. Cf. sobre isto Wadle, Alles- oder Nichts-Prinzip und Reduktionsklausel, em: VersR 1971, 485-493.

18. Mencionados sejam o transporte gratuito (BGHZ 18, 149, 158 e sg.) e relaçóes no plano do direito de familia entre 0 autor do dano e a pessoa lesada. (Schiemann, pp. 13 e sgs.; Herm. Lange, p. 443).

19. $B G H Z 18,149,159-167$

20. BGHZ 18, 149, 159 .

21. OLG Koblenz, VersR 1989, 629; OLG Köln, VersR 1989, 708; Herm. Lange, p. 538, anotaçōes 72, 443 e sg.

22. Schwerdtner, em MünchKomm BGB, 2. ed. 1984, §12 Num. marg. 299, 299, menciona esta circunstância como primeira de "várias circunstâncias curiosas no direito vigente da responsabilidade".

23. Cf. sobre isto E. Lorenz, Immaterieller Schaden und "billige Entschädigung in Geld", 1981, pp. 76 e sg. com mais outras fontes; e posterior, p. 24 e sgs.

24. BGHZ 18, 149, $167 \mathrm{sg}$.

25. Herm. Lange, p. 436; cf. sobre isto também BGH, VersR 1961, 164; e mais posterior, p. 268, anotação 144 
da hoje. ${ }^{26}$ Essencialmente, duas são as objeções levantadas contra a dupla função da indenização por dano pessoal. A crítica mais antiga pretende que a indenização seja restrita à função de compensação. Contra a função de satisfação foi especialmente objetado que ela se movimenta perigosamente muito perto da pena privada. ${ }^{27} \mathrm{Diz}$-se, de outra parte, que ela corre solta, não tem significação, é uma equiparação meramente formal..$^{28}$ Trataremos a seguir de ambas as objeções. Primeiramente examinaremos o que se deve entender por satisfação.

\section{Conceito e Conteúdo da Satisfação}

\section{Conceito}

O BGB partiu do direito suíço, do qual retirou a idéia de "satisfação", sem se ocupar com o seu conteúdo. O conceito foi depois empregado como sinônimo de $B_{\text {Busze }}^{29}$ (multa, no sentido de pena, N.T.).

No direito suíço, a satisfação abrange tanto o elemento compensação como o

elemento Busze, ${ }^{30}$ significando, pois, ambas as funções, enquanto que o antigo direito alemão conhecia basicamente o termo no sentido de "prestação liberatória, indenização", ${ }^{31}$ não no sentido de Busze. Uma dissertação de LEIPZIG do ano de 1909, sob o título A Pretensão de Satisfação no Código Civil, ${ }^{32}$ descreveu a indenização por dano pessoal com função unicamente de compensação. Ao tempo do surgimento do $B G B$, no entanto - em adesão a v. IHERING ${ }^{33}$ vinculavam-se a esse conceito exclusivamente conteúdos penais. A exposição de motivos do $\mathrm{BGB}^{34}$ utiliza-o somente em oposição a compensação: "Ainda quando o 'dinheiro da dor' (Schmerzensgeld) não deva ser visto como satisfação da ofensa à vítima, ainda assim é indenização por alguma cousa." Analogamente, também OTTO VON GIERKE faz uma distinção: no delito a prestação substituta pode visar à satisfação ou à restauração, e ser elaborada, respectivamente, como pena privada ou indenização por perdas e danos. ${ }^{35}$ Tais enfoques não foram acolhidos pelo Grande

26. Assim também E. Lorenz, pp. 104, 115, 120.

27. Mertens, MünchKomm, 2. ed., 1986, \$847 Num. marg. 2. Assim também J. Niemeyer, Genugtuung des Verletzen durch Buße, 1972, p. 88; o mesmo, anotaçöes sobre BGH, NJW 1976, 1147, em: NJW 1976, 1792 com mais outras fontes; Hupfer, anotaçōes 1972, p. 88; 0 mesmo, anotaçöes sobre BGH, NJW 1976, 1147, em: NJW 1976, 1792 com mais outras fontes; Hupper, anotaçöes
sobre BGH, NJW 1976, 1147, em NJW 1976, 1792, 1793; F. Ebel, Zur Höchtspersönlichkeit des Schmerzensgeldanspruchs, em: sobre BGH, NJW 1976, 1147, em
VersR 1978, 204-210, 204 e sg.

28. Mertens, MünchKomm, 2. ed., 1986, $§ 847$ Num. marg. 3, assim também H. Honsell, Die Funktion des Schmerzensgeldes, em: VersR 1974, 205-207.

29. BGHZ 18,149, 155: Na função de compensação ressoa "ainda hoje algo do caracter de pena ou, falando com a expressão exacta da instituição jurídica suiça correspondente, de satisfação".

30. Sobre o direito suiço cf. Mertens, MünchKomm. 2. ed. 1986, $\S 847$ Num. marg. 2; e Nehlsen-v. Stryck, Schmerzensgeld ohne Genugtuung, em JZ 1987, 119-127, 125.

31. DRW IV, 1939-1951, Coluna 245, mais outros significados: "realizaçăo suficiente", "cauçāo".

32. Karl Hermann Lang

33. Cf. sobre isto Nehlsen-v. Stryck, 123; e Pecher, AcP 185, 390 e sg.

34. Motivos sobre o projeto de um Código Civil para o Reino Alemão, 2. vol., direito das obrigaç̋̃es, 1888, p. 802

35. v. Gierke, Deutsches Privatrecht, Bd. 3, Schuldrecht, 1917, p. 881.
Senado, embora este haja se aproximado muito deles.

Quanto à Busze, um amplo campo de conceitos se apresenta, abrangendo elementos tanto do direito penal como do direito civil. ${ }^{36}$ Essa escassa tentativa de alargar o conceito já mostra que, nesta via, o problema dificilmente pode ser resolvido a contento. $O$ que vem a ser satisfação, só pode ser determinado a partir do seu conteúdo e não com frases brilhantes. ${ }^{37}$ Até aqui, o BGB utilizou o termo simplesmente como um conceito natural de Busze, que melhor expressa aquilo a que ele se refere.

\section{Conteúdo}

Cabe, pois, a seguir, verificar o modo como a jurisprudência aplicou e preencheu o conceito. A decisão do Grande Senado é inconclusiva quanto a este problema. Mesmo assim, a redação escolhida - o ofensor deve ao ofendido uma satisfação pelo que lhe fez - permite ver que a função de satisfação não se orienta tendo em vista somente o lesado, dado que insere também o causador do dano. Isso decorre, inclusive, da possibilidade de, na determinação do montante da indenização do dano imaterial, serem levadas em conta as circunstâncias concernentes ao ofensor.

Tudo aquilo que o BGH dispôs-se a aceitar como compreendido na satisfação apareceu mais tarde, principalmente nos

\section{DRW II, 1932-1935, colunas 655-657.}

37. Hirsch, Zur Abgrenzung von Strafrecht und Zivilrecht, em: Festschrift für Karl Larenz zum 70. Geburtstag, 1969, pp. 304-327, 306. 38. BGHZ 35, 363, 368 .

39. BGHZ 35, 363, 369 .

40. BGHZ 35, 363, 369, outra opinião: Schwerdtner, Das Persönlichkeitsrecht in der deutschen Zivilrechtsordnung, 1977, pp. 281 e passim. julgados sobre violação do direito de personalidade. O "caso Ginsing-Wurzel" foi conduzido no sentido de que "a recusa de indenizar danos imateriais na proteção dos direitos de personalidade" significaria que "a ofensa à dignidade e à honra das pessoas não teria sanção no ordenamento civil, que expressa os valores essenciais feridos e diz que o ofensor deve uma satisfação ao atingido pela injustiça", 38 "Só é possível oporse contra tais desonestas ambições de lucro quando sobre elas pesa o risco de uma sensível perda material." ${ }^{39}$

Com isso, o BGH indicou, como finalidades da função de satisfação, expressamente a sanção e implicitamente a prevenção. A tríplice finalidade da satisfação, no início mencionada, recebeu assim o reconhecimento da mais alta corte de jus. tiça, o mais tardar em 1961. E não ficou restrita aos casos de violação do direito de personalidade, que se caracterizava justamente pelo fato de a "função da satisfação do 'dinheiro da dor' (Schmerzensgeld) situar-se totalmente em primeiro plano perante a função de indenização". ${ }^{40}$

Em 1975, o BGH foi até mesmo além disto: A função de satisfação "deve adquirir especial importância quando, como aqui, o lesado (como pressuposto da sua própria pretensão) ainda vive, e a anulação da sua personalidade sujeita a danos tira-lhe o conhecimento tanto da sua perda como do

Revista da Faculdade de Direito da UFRGS, v. 17, 1999

Revista da Faculdade de Direito da UFRGS, v. 17, 1999 
significado da compensação". Não é contrário a isto, ao ver do $\mathrm{BGH}$, o fato de o ofendido nada poder sentir relativamente à satisfação. Com isto - assim o BGH - mesmo que não se atenda à figura jurídica da satisfação, ainda assim "um aprimorado conceito de expiação, não necessariamente criminal no sentido do regramento legal (...) impõe que um pesado prejuízo causado ao ser humano não deve permanecer sem uma reparação, no mínimo simbólica". Esta reparação exige expiação "de modo simbólico". 41 "Isto significa que o pagamento deve atingir os ofensores como um sacrifício palpável." ${ }^{42}$

Por fim, como resultado provisório, resta afirmar que a satisfação, tal como a entende a jurisprudência, deve atuar em primeira linha sobre o ofensor; além disto e de modo preventivo, também sobre o público.

\section{Limites da indenização da satisfação e da pena}

Desse modo, em qualquer caso, a função de satisfação vai além do princípio da compensação adotado no direito alemão relativamente à indenização por perdas e danos. $\mathrm{O} B G B$, ao preencher a pretensão de indenização por perdas e danos, consi-

\section{BGH JZ 1976, 559, 560}

42. BGH JZ 1976, 559, 561 .

43. Herm. Lange, p. 9

44. Larenz, SchuldR, Bd.1, §27 I, p. 423; Herm. Lange, p. 10.

45. De certo modo o caminho contrário toma Grossfeld (Die Privatstrafe. Ein Beitrag zum Schutz des allgemeinen Persőnlichkeitsrechts, 1961 , p. 75 e sgs. Ele parte da idéia de que a indenização em geral pode sevir para objetivos penais.

46. Mertens, MünchKomm, 2. ed. 1986, $§ 847$ Num. marg. 3; parecido também H. Honsell, $205 \mathrm{sg}$

47. De outra maneira porem, o "Allgemeines Landrecht für die Preußischen Staatende" 1794, Parte I, Tit. 5 \$ 285-291; Tit. 6 \$ 10$16,85-88,93-95 ;$ Tit. 16, § 17

48. Motivos, Vol. 2, pp. 17 e sg.; cf. posterior a anotação 96; assim também Herm. Lange, pp. 12 e sg. conta na função de compensação, isto só será possível, quando muito, na elevação do montante da compensação. Uma soma indenizatória absoluta, necessária, pode não ser alcançável na culpa levíssima. Contrariamente, todo raciocínio tendente a assegurar uma soma superior à compensação faz explodir o princípio da indenização. ${ }^{49}$ Precisamente neste sentido, no entanto, é que a jurisprudência admite ser levada em conta a culpa. O raciocínio retrata fielmente a nova doutrina, que procura explicar o ' $\mathrm{di}$ nheiro da dor' do modo mais completo possível, a partir de uma "bem compreendida compensação". Nada se lucra fazendo com que o único firme e bem consolidado conceito dogmático de que dispomos neste assunto - o princípio da indenização - seja desviado e alargado para além dos casos de dano regrado, apenas para evitar um outro conceito de difícil definição. Nada muda com isto: o problema é deslocado, mas não solucionado.

Entrementes, voltar-se para o ofensor ou, dito de outro modo, para o agente, é típico do direito penal. Não se deve, desse modo, postular nenhuma recaída no assim chamado direito penal do agente, ${ }^{50}$ e sim ter em conta as circunstâncias, uma vez que nosso direito penal é direito penal de culpabilidade, não direito penal de resultado..$^{51}$ $\mathrm{O}$ direito penal interessa-se pelo agente e

49. Assim também E. Lorenz, pp. 126 e sg.

50. Cl. sobre isto Lenckner, Schönke-Schrő́der, Strafgesetzbuch, Kommentar, 23. ed., 1988, nota prévia dos $\$ \S 13$ e sgs, Num. marg. 103. "O agente é punido pelo que ele fez, e não pelo que ele é." (Num. marg. 105).

51. Cf. sobre isto Lenckner, Schönke-Schrőde, nota prévia $\$ \$ 13$ e sgs., Num. marg. 103.

52. Assim também Hirsch, p. 307.

53. Windscheid, Lehrbuch des Pandektenrechts, Vol. II, 3. ed., 1873, \$455 anotação 31, p. 660. pelo ato. A indenização por perdas e danos e a pena diferenciam-se, assim - no julgamento de um mesmo ato - pela razão de que uma compensa os danos causados à vítima, enquanto a outra visa a produzir efeito sobre o agente, para que, conforme a finalidade da pena, o ato seja expiado, fiquem impedidos outros atos do agente, etc. De uma parte, põe-se de lado a nenhuma valia do resultado e, de outra, a nenhuma valia do ato.

De acordo com esta distinção, seria de agregar à pena, sem quaisquer proble. mas, no mínimo duas das três finalidades da satisfação (sanção e prevenção) sem que necessariamente se pense em pena criminal. ${ }^{52}$ Todavia, também a primeira finalidade (apaziguamento do lesado) é de atribuir à pena, quando nela se divisa uma saída para a outrora aí inserida vingança. Evidentemente, isto só tem procedência quando as conseqüências de um ato ilícito, que seja ao mesmo tempo delituoso, lógica e inarredavelmente constituem quer perdas e danos quer pena, consoante postulava WINDSCHEID: Quando o dinheiro da dor (Schmerzensgeld) "não é indenização (Ersatz) tem de ser pena (Strafe)". ${ }^{53}$ Seria diferente se entre ambas houvesse um autêntico terceiro - a satisfação.

HANS STOLL, em opinião manifestada ao $45^{\circ}$ Congresso Alemão de Juristas 
em 1964, ${ }^{54}$ empreendeu a tentativa de "distinguir a pena da satisfação", apesar da carga penal desta, e transformá-la em um instituto jurídico autônomo. Ele desenvolveu a definição, muito citada, de que "satisfação em sentido jurídico (...) é apaziguamento da vítima pela expiação do ato". ${ }^{55}$ Contudo, com esta formulação ainda não fica respondida a questão de saber se deve ser aberta uma categoria própria ou se com isto descreve-se meramente um reflexo, que tanto a indenização como a pena poderiam solucionar. Ambas são adequadas a provocar no lesado um sentimento de contentamento, de satisfação. Isto, porém, não pode ser algo autônomo, de permeio entre a indenização e a pena. A fórmula é efetivamente apropriada para delimitar a pena privada da criminal, mas não para diretamente separar a pena de uma terceira categoria. A pena criminal serve à "satisfação da comunidade jurídica", a pena privada à satisfação da vítima. ${ }^{56}$ Conseqüentemente, a tentativa de STOLL de definir a satisfação como uma expiação que não é autônoma, "mas (...) meio de atingir um fim, especialmente o apaziguamen-

to do lesado", 57 tem de ser vista como fra cassada. ${ }^{58}$ De conformidade com o seu conteúdo, a satisfação é pena privada; não existe nenhum terceiro de permeio entre a inde nização por perdas e danos e a pena. O próprio STOLL, a final, bem constatou isto, quando do confronto que fez com a "injúria" romana, pela qual a satisfação foi "ao mesmo tempo uma pena horrível", ${ }^{59}$ bem como quando fala da sua proposição de dar uma base legal à pretensão de satisfação, para que o brocardo Nulla poena sine lege (art. 103, II, da Constituição Federal) não seja desrespeitado. ${ }^{60}$

Para STOLL - como, semelhantemente, também para o $\mathrm{BGH}$ - o conceito de satisfação exerce funções paliativas. ${ }^{61}$ Ajuda a evitar o uso da expressão pena privada, sem fornecer seu conteúdo. ${ }^{62}$ A cousa torna-se ainda mais evidente no idioma alemão, que até mesmo aceita isto abertamente e emprega "satisfeito (...) a palavra alternativa", que "evita expressões tais como expiação e pena privada, as quais ou caíram em desuso ou provocam colisões". ${ }^{63}$ Segundo HERMANN LANGE, "com isto não se

54. H. Stoll, Empfiehlt sich eine Neuregelung der Verpflichtung zum Geldersatz für immateriellen Schaden? Parecer para 045 . congresso jurídico alemão, discussões do 45. congresso juridico alemão [em] Karlsruhe 1964, Vol. I (Parecer) Parte 1, 1964, p. 151. 55. H. Stoll, Parecer, p. 152

56. LG Flensburg, VersR 1988, 740: "Pois o processo penal serve em primeiro lugar para a satisfação da comunidade jurídica, $e$ menos para a da vítima. " H. Stoll, Parecer, p. 152.

57. H. Stoll, Parecer, p. 152.

58. Assim também Nehlsen-v. Stryk, 125

59. H. Stoll, Parecer, $p$. 153. Assim também Kaser, Das Römische Privatrecht, primeira parte. Das altrömische, das vorklassische und klassische Recht, 2. ed., 1971, pp. 610, 623 e sg., 625, 501: "Busze (poena) "= Ser punido pela injustiça.

60. H. Stoll, parecer, p. 155. Esta contradição também já apontou Hirsch, p. 326.

61. Hirsch, p. 310 , fala do "rótulo" da função de satisfação.

62. Assim também Hirsch, p. 309: "Porém esta análise da satisfação não é outra coisa senão a caraterização precisa da pena privada antiga."

63. Deutsch, Haftungsrecht, p. 473. Ele fala neste contexto de uma satisfaçăo "distante do prejuízo e perta da sançăo".

Revista da Faculdade de Direito da UFRGS, v. 17, 1999 chega a criar uma categoria autônoma, passível de ser diferenciada da pena. ${ }^{64}$ GERNHUBER fica diante do seguinte dilema: "A idéia de satisfação não deve ser sobrecarregada com as características da pena; mas, sem isto, ela permanece, no mínimo, difusa." 6

\section{Evolução Histórica}

\section{Até a promulgação do BGB}

Este resultado foi alicerçado na evo lução histórica do instituto. Na verdade, a suposição do BGB, de que nas normas legais do Séc. XIX sobre dinheiro da dor "ainda parcialmente se fez sentir a sua origem no direito penal" ${ }^{66}$ não é identificável, mas ela efetivamente vinculou-se à evolução do último século. Contudo, também algumas leis locais do Séc. XVIII já asseguravam o dinheiro da dor, ${ }^{67}$ mas a discussão que re sultou desse contexto somente no século seguinte veio a ser debatida de modo completo.

A causa desse debate foi a circuns tância de que o dinheiro da dor era estranho ao direito romano e, conseqüentemen-

te, havia um especial constrangimento quanto à fundamentação, quando fosse necessário referi-lo ao que regularmente aconteceu. Serviam de fundamento tanto o direito penal como a função de compensação. Durante muito tempo o dinheiro da dor foi reconhecido pelo direito comum com base numa destas fundamentações. ${ }^{68}$ Poucos autores e tribunais negaram a sua existência. ${ }^{69}$ A natureza jurídica do instituto permaneceu duvidosa. Somente após a fundação do Império Alemão (Reichsgründung) é que a teoria da compensação foi aos poucos predominando. ${ }^{70} \mathrm{De}$ cisivo para isso foi, por fim, um pequeno estudo de CARL GEORGE V. WAECHTER, do ano de 1874 , sobre "A Busze nas Ofensas e nos Ferimentos Corporais segundo o atual Direito Comum". Suas exposições sobre a natureza jurídica do dinheiro da dor interessam ainda hoje, pois ele elaborou um confronto altamente elucidativo, que nada perdeu em atualidade. O dinheiro da dor, concebido como pena, deveria determinar-se segundo fatores muito diversos daqueles compreendidos na indenização. Esta é determinada simplesmente em conformidade com o tipo e ta-

64. Herm. Lange, p. 437

65. Gernhuber, Bürgerliches Recht, 2. ed. 1983, p. 365 .

66. BGHZ 18, 149, 155.

67. Sobre o desenvolvimento mais antigo cf. Nehlsen-v. Stryk, 121

68. Cf. sobre isto Nehlsen-v.Stryk, 121

69. O OAG Celle (Seuffert's Archiv 27, 30 (1839) o recusou porque seria em desacordo com o direito romano. Cf. sobre isto Wieling, Interesse und Privatstrafe vom Mittelalter bis zum Bürgerlichen Gesetzbuch, 1970, p. 147.

70. Cf. sobre isto Nehlsen-v.Stryk, 122 anotação 36 . Todavia ela não leva em conta, como antes dela também não o redator do BGB v. Kübel (cf. mais adiante anotação 76) a maior parte da Literatura germanistica, que na medida em que a indenização do dano moral em geral foi mencionada - quase unanimemente declarou-se pela natureza privada da pena: $F$. Ortloff, Grundzüge eines

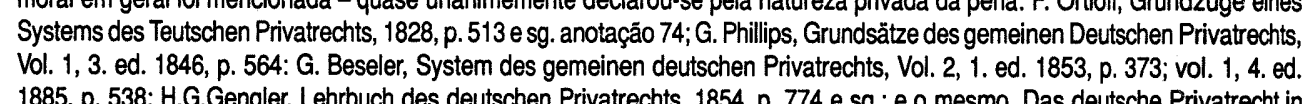
1885, p. 538; H.G.Gengler, Lehrbuch des deutschen Privatrechts, 1854, p. 774 e sg.; e o mesmo, Das deutsche Privatrecht in seinen Grundzüge für Studierende, 1892, p. 498. 
manho da dor do lesado, não segundo o tipo e tamanho da culpa do lesado (sic - des Verletzten). ${ }^{71}$ Se coubesse ao dinheiro da dor uma função penal, ela deveria "ser determinada segundo o tipo e a gravidade do delito cometido". 72

O Tribunal do Império, em decisão de 17 de novembro de $1882,{ }^{73}$ admitiu o direito ao dinheiro da dor como tal, qualificando-o, no entanto, não como pena privada em sentido técnico, mas como uma pretensão indenizatória de direito civil "por motivo de dores ilegalmente sofridas". Conseqüentemente, decidiu a seguir que "a consideração da magnitude, violência e duração da dor sofrida constitui o elemento decisivo". ${ }^{74}$

\section{A origem do art. 847 do BGB}

Desse estado da discussão foi que partiu a Comissão do BGB. É significativo que, em conexão com o tema versado, foram estabelecidas fundamentalmente as posições contraditórias: indenização do dano ou pena privada. Apenas alguns poucos autores conceberam o dinheiro da dor como sendo composto por ambos os elementos. ${ }^{75}$

Embasado nisto, o redator do Anteprojeto da Primeira Comissão para a elaboração do Projeto do Código Civil, v.

71. v. Waechter, p. 75

72. v. Waechter, p. 76

73. RGZ 8,117

74. RGZ 8, 117, 118. Cf. sobre isto também Nehlsen-v. Stryk, 122.

75. Stobbe, Handbuch des Deutschen Privatrechts, Bd.3, 1878, p. 418; e O. v. Gierke, Deutsches Privatrecht, Vol. 3, pp. 958, 971; ambos em si contraditorios. Eles partem da funçăo simples de substituiçăo, mas chegam à actio mixta.

76. W. Schubert (Editor), Die Vorentwürfe der Redaktoren zum BGB. Recht der Schuldverhältnisse, parte 3, Parte especial II, 1980, pp. 819-823, 821.
KÜBEL, distinguiu os motivos, divergentes entre si, justificadores da delimitação do dinheiro da dor: "Quanto a saber que circunstancias devem ser levadas em conta na determinação do montante do dinheiro da dor, não existe nenhum consenso, o que, ao menos em parte, guarda coerência com a diversidade de opiniões sobre a natureza do dinheiro da dor, como pena ou indenização. Em um julgado (...) foi declarado que na quantificação do dinheiro da dor têm de ser levados em conta o grau de culpa e o volume do patrimônio do réu, porque a pretensão não se funda na lex Aquilia, mas no direito alemão e na eqüidade natural (...) Contrariamente, de outro lado, em consideração ao caráter de indenização do dinheiro da dor, decidiu-se que o grau de culpa e a situação patrimonial do culpado não devem ser consideradas, mas sim, o que deve ter lugar é a medição da magnitude, tipo e duração das dores sofridas." ${ }^{\prime 6}$

Embora o Anteprojeto da Primeira Comissão tenha seguido o texto do Projeto de DRESDEN, que não previu nenhum regramento do direito da dor, decidiu, todavia, a Primeira Comissão admitir uma pretensão do dinheiro da dor no art. 728 do projeto do $\mathrm{BGB}$, e na verdade paralelamente ao art. 231 do StGB (Código Penal). "Quando (...) o juiz do crime, está autorizado também, em razão de prejuízo não patrimonial causado ao lesado, a infligir uma Busze a pedido deste ..., igual competência deve ter também o juiz do cível". ${ }^{77}$ Mas a Busze, no sentido do art. 231 do StGB, foi ao mesmo tempo a história da origem da pena privada e da indenização do dano. ${ }^{78}$ Todavia, permanece em aberto a questão de saber se apenas a possibilidade de infligir devia ser transferida ao $\mathrm{BGB}$, ou igualmente o seu conteúdo. A probabilidade está com a primeira. $\mathrm{O}$ legislador conscientemente não quis decidir esta discutida questão da natureza do dinheiro da dor. ${ }^{79} \mathrm{~A}$ Segunda Comissão não retomou de modo algum o problema, senão que discutiu meramente a extensão - recentemente rejeitada - do preceito também às ofensas contra a honra. ${ }^{80}$ Com isto, no mínimo, nada se decidiu contra o caráter penal do art. $847 .^{81}$

\section{A jurisprudência do \\ Tribunal do Império}

O problema da natureza jurídica do dinheiro da dor inicialmente retrocedeu, porque a questão de sua validade encontrava agora resposta na lei..$^{82}$ Daí, porém, não se pode tirar a conclusão de que as decisões judiciais tenham resolvido o proble- ma favoravelmente à função de compensação. Na verdade, o III Senado do Tribunal do Império, no ano de 1910, recusou levar em consideração o grau de culpabilidade na quantificação do dinheiro da dor, ${ }^{83}$ porém, em 1932, o VI Senado chegou ao resultado oposto. ${ }^{84}$ Sem dirigir-se expressamente a um caracter penal, o Tribunal empregou em sua fundamentação argumentos que até então, na discussão, eram desenvolvidos a partir do caráter penal do dinheiro da dor. $O$ ponto de partida para o Tribunal do Império como mais tarde também para o $\mathrm{BGH}$ - foi a "eqüitativa" (billige) indenização em dinheiro do art. 847: "Numa decisão segundo a eqüidade (Billigkeit) devem, em princípio, ser apreciadas todas as circunstâncias do caso (...) e não cabe aí indagar porque uma culpa especialmente grave do autor do dano também não deva ser considerada, sobretudo quando ela é capaz de atuar amargamente sobre o lesado. A eliminação desta circunstância seria arbitrária." ${ }^{85}$

\section{A jurisprudência do BGH}

Contrariamente à doutrina dominante e à jurisprudência, que aderiram à últi-

77. Motivos, Vol. 2, p. 800, Assim também o Comentário do Bürgerliches Gesetzbuch de Planck, 4. ed. 1928, impressão nova 1981, § 847 anotaçăo 1.

78. v. Waechter, pp. 22, 30, 40. Sobre a doutrina dominante posterior e crítica sobre ela cf. H. Stoll, Schadensersatz und Strafe. Eine rechtsvergleichende Skizze, em: lus Privatum Gentium. Festschritt für Max Rheinstein, Vol. II, 1969, pp. 569-590, 580 anotação 41.

79. Cf. por ex. os motivos, Vol. 2, p. 802 .

80. Os protocolos da commissão para a segunda leitura do projeto do Código Civil, Vol. II, direito das obrigaçōes, 1898, p. 640 e sg. 81. Assim também Nehlsen-v. Stryk, 124

82. Cf. sobre isto por ex., o comentário de Planck, que nao se pronuncia sobre este problema.

83. RG, BayRpt.Z. 1910, 217. Seguem-no Staudinger e RGRK. (Depois de RGZ 136, 60, 61.)

84. RGZ 136, 60. O III. Senado abriu mão da sua jurisdiçăo (RGZ 136, 60,62).

85. RGZ $136,60,62$ 
ma decisão, ${ }^{86}$ o III Senado Cível do BGH recusou levar em conta a situação patrimonial do causador do dano na medição do dinheiro da dor. Diferentemente do Tribunal do Império, o BGH aceitou neste julgamento a base dogmática da disputa. "Para decidir esta questão cumpre atentar para o sentido e a finalidade da eqüitativa indenização em dinheiro segundo o art. 847 do BGB. O teor da lei não exige que se leve em conta a situação patrimonial do lesado. Por outro lado, ela poderia ser admitida, caso no art. 847 do BGB se cuidasse, ainda que meramente em sentido amplo, de preceito penal." ${ }^{87}$ Isto foi negado pelo $\mathrm{BGH}$, com base numa interpretação histórico-genética ${ }^{88}$ pouco convincente, mas também em função do teor e do emprego sistemático da mesma. ${ }^{89}$ Decisivo para a estimação do dinheiro da dor "deve, portanto, ser o dano de feitio não patrimonial produzido no lesado pelo ato ilícito"..$^{90}$

O entendimento do III Senado Cível foi seguido pela maioria dos tribunais de instância. ${ }^{91}$ Contudo, alguns Tribunais de Relação opuseram-se a esta praxe sentencial. O tribunal de $\mathrm{HAMM}^{92}$ resolveu aproximadamente considerar a situação financeira do autor do dano, e também a do lesado. Mais longe ainda foi a Relação de OLDENBURG:"3 "Uma indenização

86. Documentação sobre isto: $\mathrm{BGHZ} 7,223$, Documentação sobre a opiniăo minoritária: 224

87. BGHZ 7, 223, 224. Cf. sobre esta decisão também Schieman, pp. 5-8.

88. $\mathrm{BGHZ} 7,223,224 \mathrm{esg}$

89. BGHZ 7, 223, 225 e sg.

90. BGHZ 7, 223, 226. Sobre a fixaçăo e interpretação do conceito indenizaçăo eqüitativa "cf.: BGHZ 7, 223, 229.

91. Como último: OLG Nürnberg, VersR 1955, 218; OLG München, VersR 1955, 553; OLG Celle, VersR 1955, 621

92. VersR $1955,86$.

93. DAR 1955, 110, Frases 2 e 3 da ementa; = VersR 1955, 286, em parte năo públicado.

94. BGH, VersR 1955, 295. tentiva, no sentido do art. 847 do BGB, pode muito bem ser entendida apenas como consideração de todas as circunstâncias do caso, resultantes de uma avaliação eqüitativa. Uma dessas circunstâncias pode também, contrariamente à interpretação do $\mathrm{BGH}$, consistir na situação econômica do causador do dano, mas não necessariamente. Também o grau de culpa do ofensor tem de ser considerado, de modo que a diversidade do grau de culpa de vários responsáveis pode levar a diferentes avaliações do dinheiro da dor".

Também o VI Senado quis, na revisão, divergir do entendimento do III Senado, mas viu-se impedido de fazê-lo em face do apego do III Senado à sua antiga jurisprudência, e assim propôs ao Grande Senado a seguinte resolução: "Se na estimação do montante de uma indenização eqüitativa em dinheiro segundo o art. 847 do BGB (dinheiro da dor) devem ser consideradas todas as circunstâncias, assim também deverá ser no tocante à situação patrimonial e ao grau de culpa do responsável. ${ }^{194} \mathrm{O}$ rande Senado respondeu a pergunta com os argumentos conhecidos.

\section{Resultado provisório}

Desta pesquisa, resultou até agora ue a recepção do art. 847 do BGB deixou em aberto a contenda quanto a saber se o dinheiro da dor deve ser entendido como pena privada ou como indenização. ${ }^{95} \mathrm{Na}$ verdade, o conceito de "indenização" e a posição da norma na lei ${ }^{96}$ podem acenar para uma pretensão de indenização, mas não a configuração do preceito como um todo: a decisão do legislador, de que a pretensão do art. 847 só é herdável dentro de certos pressupostos (dependência jurídica, reconhecimento contratual) acentua a sua origem de pena privada, porquanto uma pretensão de indenização seria livremente herdável $1{ }^{97}$ Por conseguinte, tem-se de partir do fato de que o art. 847 deve ser tido como exceção à regra segundo a qual o direito civil não deve perseguir fins penais, mas, inobstante isto, esse art. tem um caráter penal, pelo menos não o exclui. ${ }^{98} \mathrm{~A}$ decisão do Grande Senado, conseqüentemente, não pode ser vista como "ressurgimento da pena privada", 99 mas simplesmente como uma retomada de consciência do real conteúdo do art. 847, ${ }^{100}$ que contém, desde o início, um elemento penal.

95. Nisto assenta principalmente Schwerdtner Persőllichkeitsrecht pp. 282 e passim. Porem há dúvidas metódicas contra a sua interpretaça; ela tem tracos fortes da jurisprudência de conceitos e exclui todas as outras possibilidades de intrepretaçăo. Cf́. também a interpretação literal contrária de v. Waechter, pp. 5 e sg.

96. Uma indenizaçăo por dano moral, denominada expressivamente como pena privada, certamente nao teria podido ter uma outra posiçáa na lei.

97. Cf. sobre isto Schubert, Vorlagen, p. 822; mas também os Motivos, Vol. 2, p. 802 (No plano do direito comum é discutido se é herdável a pretensäo à indenização por dano moral. Esta questão se relaciona com a questăo de saber se a indenização por co os Mre "A id pretensão permaneça do mesmo modo na mão do lesado [atingido]. "

98. Motivos, Vol. 2, p. 17 e sg.: "A aplicação de aspectos moralizantes ou de direito penal deve ser inteiramente afastada ao serem determinadas as conseqüèncias civis do comportamento ilicito e ilegal."

99. Assim porém, Hirsch, p. 310.

100. Assim também Nehlsen-v. Stryk, 124

101. Assim também Hirsch, p. 310 
ção, situam-se eles integralmente na tradição da teoria da pena privada.

Finalmente, mostrou-se ainda que a decisão do Grande Senado não está de modo algum iniciando uma moderna jurisprudência do dinheiro da dor. ${ }^{102}$ Competelhe, antes, somente a importante missão de esclarecer e indicar o caminho. ${ }^{103}$ Além dis to, cabe-lhe o mérito de ter reavivado, e trazido de volta à consciência, as bases da discussão que foi sepultada durante os primeiros cinqüenta anos de vigência do BGB.

\section{Legitimidade da Função de Satisfação como Pena Privada}

De acordo com o teor da norma, como também segundo a sua evolução histórica e a aplicação que recebeu nos tribunais, o dinheiro da dor legitima-se também como pena de direito privado. Mas isto contrariamente a algumas vozes na literatura jurídica - não significa que a função de satisfação possa só por isso ser rejeitada. É necessário primeiramente verificar, minuciosamente, as razões que fazem com que uma pena privada seja ilegítima. ${ }^{104}$

\section{Considerações de ordem constitucional}

Examinemos, inicialmente, os preceitos da Constituição. Cabe-lhes o maior peso quando o que se procura é legitimar. Conforme já referido, houve reiteradas dúvidas quanto a ser a função de satisfação compatível com o art. 103, II, da Constituição (Nulla poena sine lege) por motivo de falta de fundamento legal. ${ }^{105}$ Afora isso, foi afirmada a proibição da duplicidade de pena (Ne bis in idem, art. 103, III, da Constituição) ${ }^{106}$ e a garantia do devido processo legal (des gesetzlichen Richters). ${ }^{107}$

Estas considerações mostraram-se enganosas. De um lado ignoram que o art. 847 contém função de pena, por isso não lhe falta fundamento legal. De outra parte, elas repousam numa interpretação por demais ampla do art. 103, II, da Constituição, que na verdade vale tanto para as penas criminais como também, em princípio, aproximadamente, para as penas disciplinares, ${ }^{108}$ mas não para as penas privadas. Com razão, decidiu o BVerfG (Tribunal Federal Constitucional) ${ }^{109}$ que o dinheiro da dor “embora 'elementos penais' não lhe sejam
102. Então O BGH não "levantou um aspecto completamento novo sobre a indenizaçăo em dinheiro por danos pessoais". Mas assim H. Honsell, VersR 1974, 205-207, 205

103. Assim também Pecher, AcP 185,385

104. Assim também Hirsch, p. 310.

105. Bötticher, Die Einschränkung des Ersatzes immateriellen Schadens und der Genugtuungsanspruch wegen Persönlichkeitsminderung, em: MDR 1963, 353-360, 359 e sg.; H.Stoll, Parecer, p. 155 e Hirsch, p. 326. Cf. sobre ist também Gersönlichkeitsminderung,

106. Hirsch p. 325.

107. Bötticher, Relatório, em: Verhandlungen des fünfundvierzigsten Deutschen Juristentages Karisruhe 1964, Vol. II Relatórios da sessão, 1965, pp. C7-C29, C18.

108. Dürig, em: Maunz/Dürig, Grundgesetz Kommentar, Vol. 4, 1960, Art. 103 II, IV 4 b e c.

109. BVerfGE 34, 269, 293. No caso de violação da personalidade, para a qual realmente falta a base legal. Assim também P. Kunig, em: I. v. Münch, Grundgesetzkommentar, Vol. 3, 2. ed. 1983, Art. 103, Num. marg. 20.

Revista da Faculdade de Direito da UFRGS, v. 17, 1999 de todo estranhos" - não é nenhuma pena no sentido deste preceito constitucional (art. 103, II, da Constituição). Faltam-lhe todos os característicos estigmatizantes da pena criminal. Não é prevista pena de privação de liberdade, como também a correspondente pena substitutiva (Ersatzfreiheitsstrafe) e não há inscrição no registro penal. Com isto caem, igualmente, as críticas a respeito da dupla punição. ${ }^{110}$

\section{Desrespeito à divisão das funções}

Depois que as considerações de direito constitucional, constantes da decisão do BVerfG do ano de 1973, perderam muito de sua força destruidora, foi ainda especialmente criticado o desrespeito à "divisão das funções do direito civil e do direito penal". 111 O direito civil não deve retirar do direito penal nenhuma de suas tarefas. Em estreita correlação com isto está o argumento de que a introdução da pena privada é um anacronismo, significa um atavismo ju rídico, uma recaída "num anterior grau de evolução do direito", uma desestatização parcial da justiça penal. ${ }^{112}$

Este argumento perde muito do seu peso pela razão de que o próprio BGB par- te de uma função penal do dinheiro da dor, ou pelo menos não a exclui. Mas, ainda quando este posicionamento inicial não seja aceito, restaria o questionamento da evolução da política criminal. Na medida em que certas áreas do direito penal venham a ser descriminalizadas ${ }^{113}$ - e isto, de certo modo, no presente contexto aplica-se ao menos a uma das duas situações da vida suscetíveis de dinheiro da dor, o direito do médico ${ }^{114}$ - surge a questão de saber se, com isto, deverão ser suprimidas todas as penas ou somente a pena criminal. Com efeito, descriminalização não quer dizer que toda e qualquer sanção deva ser direta e necessariamente eliminada. Pode subsistir uma necessidade de punição, o que de regra ocorre. Para atender a esta neces. sidade devem ser abertos outros caminhos. Para tanto servem, por exemplo, as jurisdições profissionais, e além disso o direito civil, em todo o caso o direito delitual (Deliktsrecht). Os direitos civil e penal em nenhum outro ponto se aproximam tanto entre si como em matéria de atos ilícitos. De certo modo são tratadas aqui as conseqüências jurídicas civis e penais do mesmo fato. Com razão acentua-se o parentesco próximo entre a indenização do dano e a

110. Assim também Grossfeld, p. 123

111. Hirsch, p. 306.

112. Hirsch, p. 317. Mais moderado Herm. Lange, p. 12 e sg

113. Isto pode se efetuar tanto por medidas energicas do legislador como por uma evolução gradual. Pecher, AcP 185, 391, fala neste contexto do "direito penal enfraquecendo".

114. Ulsenheimer, Arztstrafrecht in der Praxis, 1988, p. 5, sustenta ser de limitar "a responsabilidade penal do médico na área da lesão por erros graves de tratamento" e reclama que essa idéia quase náo é discutida. Por outro lado, H. Franzki (recensáo: Medizin-
Haftpflichtschäden, NJW 1989, 2936 e sq., 2937), quanto ao "direito penal enfraquecendo", entende "que o ajuizamento do processo penal contra médicos é normalmente embaraçoso para a realização de pretensōes civis". A isto chegam pelo menos alguns tribunais, considerando que nos processos de responsabilidade médica apenas excepcionalmente ocorre uma suspensão do processo por causa de um processo penal ou procedimento de investigação estatal." (OLG Köln, VersR 1989, 1201, jurisdiçáo permanente). 
pena. ${ }^{115}$ Esta afinidade, até o ano de 1974, recaiu sobre os arts. 188 e 231 do Código Penal, que permitia ao juiz do crime proferir, paralelamente à pena, uma Busze com função de compensação. ${ }^{116}$ Coisa semelhante vige hoje para os tributos do art. 56-b do Código Penal. Se o direito penal está parcialmente se retirando de uma área dos impropriamente chamados - atos ilícitos, nada mais natural do que destinar ao direito civil, no correspondente passo, os encargos liberalizantes. Semelhante destinação de tarefas favoreceria também a compensação direta agente/vítima.

Em complementação, é de examinar se o direito civil detém congruentemente a renúncia à pena privada ou se, antes, acolhe funções penais. ${ }^{117} \mathrm{O}$ direito de indenização por perdas e danos conhece a prevenção como um oportuno subproduto, todavia somente até onde chega a compensação. ${ }^{118}$ Cabe também mencionar, nesta correlação, a pena contratual. Ela não é, quer por sua conformação legal, quer por seu efeito na prática, somente a totalização das perdas e danos. As regras sobre ônus da prova, relativas a violação grosseira de deveres profissionais, igualmente não são isentas de certo caráter penal. ${ }^{119}$ Uma Busze adotada para furtos em lojas teria, para o

direito civil, a mesma função penal ${ }^{120}$ que as penas empresariais (Betriebsstrafe). ${ }^{121} \mathrm{Fi}$ nalmente, recorde-se a discussão sobre o sentido do art. 817 , parte segunda. ${ }^{122}$

Com isto, a discussão sobre anacronismo também enfraquece, abstraindo inteiramente o fato de que ela repousa num quadro histórico, excessivamente mecanicista, de um progresso retilíneo. Com razão, pôde HOLZHAUER ultimamente afirmar que "na mais recente história do direito (...) até o presente, uma tendência em direção à pena privada vem sendo novamente registrada". ${ }^{122 a}$

\section{A nenhuma importância prática do binômio: função de satisfação/pena privada}

A última objeção importante contra a função de satisfação - e, portanto, também contra a pena privada - é a de sua nenhuma importância prática. ${ }^{123}$ Apenas duas vozes manifestaram-se nesse sentido. "No que diz respeito ao dinheiro da dor, a função de satisfação é inteiramente supérflua; pois pode-se deixá-la absorvida no montante da compensação, na medida em que todo o dever de indenizar é capaz de proporcionar satisfação ao lesado, assim como, inversamente, a obrigação de pagar perdas e

115. Pecher, AcP 185, 391; ainda mais acentuando Grossfeld, p. 75 e sg., 83

116. Cf. sobre isto Herm. Lange. p. 431.

117. De direito comparado sobre isto $H$. Stoll, Schadensersatz und Strafe, pp. 570-579.

118. Herm. Lange, p. 10. Isto porém, é contestado; cf. sobre isto Meder, p. 130, anotaçăo 15.

119. Herm. Lange, p. 12.

120. Herm. Lange, p. 13.

121. Cf. sobre isto Zöllner, Betriebsjustiz, em: ZZP 1970, pp. 365-393.

122. Cl. sobre isto por. ex., Medicus, Schuldrecht II, Besonderer Teil, 4. ed., 1990, p. 302

122a. Holzhauer, Privatstrafe, in: Erler/ E. Kaufmann (Editores), HRG, Vol. 3, 1984, coluna 1993-1998, 1997.

123. Os representantes desta opiniăo mencionam normalmente apenas o acidente de trânsito; cf. por. ex., Hupfer, 785 .

Revista da Faculdade de Direito da UFRGS, v. 17, 1999

danos não raro atua perante o lesado como pena." 124 - "Como o comprova a aplicação generalizada das tabelas do dinheiro da dor a idéia de satisfação não exerce nenhum papel na quantificação do dinheiro da dor". ${ }^{125}$

A isso se opõe, contudo, uma consulta levada a efeito em $1979 / 80$, por aproximadamente $15 \%$ dos juízes do cível da Baviera. ${ }^{126}$ Cerca da metade dos consultados manifestou-se no sentido de que eles "em cada caso valorizam de igual modo a função de compensação e a função de satisfação". ${ }^{127}$ Isso, no entanto, nada significa quanto a saber se o montante do dinheiro da dor seria diferente caso a função de satisfação fosse eliminada.

124. H. Honsell, 206; seguindo-0: Nehlsen-v. Stryk, 126

125. P. Cramer/H. Kindermann, Wege zur Reform des Schmerzensgeldanspruchs, DAR 1980, 33-39, 34.

126. H.J. Musielak, Zur gerichtlichen Praxis bei der Bemessung des Schmerzensgeldes - Ergebnisse einer Befragung von Richtern em: VersR 1982, 613-618.

127. Musielak, 614.

128. Trata-se freqüentemente de casos de responsabilidade civil de trânsito, que são descritos na literatura de regra suplantando os outros casos. Coisa parecida também vale para os casos de responsabilidade civil dos médicos, que pelo seu número não podem ser esquecidos.

129. OLG Hamm, VersR 1990, 909; "No caso de violaçoes que baseiam-se em infraçōes de trânsito por negligência, a função de satisfação passa para o segundo plano."

130. Cl. sobre isto também Schwerdtner, Persönlichkeitsrecht, pp. 276 e sg.

131. Por ex. OLG Köln, VersR 1981, 690; OLG Stuttgart, DAR 1982, 400. Assim também na sua maioria a opinião na literatura.: $E$. Lorenz, p. 174; Esser/Weyers, Schuldrecht Vol. II, Partes Especial, 6. ed. 1984, p. 528. Outra opiniäo Lieberwirth, Das Schmerzensgeld, 3 . ed.. 1965, pp. 58 e sg., baseiando-se na jurisdiçäo mais antiga.

132. BGH VersR 1967, 495, 496; NJW 1977, 337, 339; VerR 1981, 677, 678. Outra coisa vale para a decisåo NJW 1982, 985, 987, onde $\mathrm{OBGH}$ recusou a revisão de um ferido que reclamou que o OLG não levasse bastante a culpabilidade em conta: "O tribunal de apelação qualificou o comportamento do réu" na primeira instância de "irresponsável" e gravemente descuidado e atribuiu-the uma "culpabilidade muito grave". Com isso ele aparentemente não negou que o réu na primeira instância agiu intencionalmente contra regulamentos de trânsito e contra tipos penais quando deixou ao volante a sua noiva de menos de 18 anos e sem licença para dirigir. Mas por isso o réu na primeira instância nâo causou intencionalmente 0 acidente, embora haja a irresponsabilidade e a leviandade peculiar do seu agir justamente na permissão intencional de dirigir sem carteira. Na sua decisão o tribunal de apelação năo esqueceu nenhuma função importante de satisfação do dinheiro da dor por danos pessoais.

133. Se o tribunal de apelação não levou amplamente em consideração as circunstâncias decisivas ou se ao ponderar violou preceitos jurídicos ou leis do pensar (BGH, VersR 1981, 677, 678; VersR 1988, 943).

134. Mas facilmente se pode àpresentar aqui também exemplos contrários: LG Duisburg, DAR 1983, 24 (Participação no trânsito com um teor de acoolemia de 2,35 \% como culpabilidade considerável); $\theta$ OLG Stuttgart, VersR 1983, 470 (culpabilidade grave do autor do dano, "que dirigiu bebado 0 automóvel que causou o acidente"). 
E mais: existem ainda casos onde a função de satisfação ganha maior relevo. Isso se vê claramente quando vários são os responsáveis pelo dano, com duvidosa intensidade de culpa. Caso semelhante já foi alvo de uma decisão do Grande Senado. ${ }^{135}$

A função de satisfação permite aos tribunais estimar diferentemente o dinheiro da dor em função do grau de culpa e atribuir a uma mesma ofensa dinheiro da dor em montante diverso. A função de satisfação ganha especial importância, e até mesmo significado constitutivo da concessão do dinheiro da dor, em hipóteses com danos muito pequenos ou muito grandes, sempre que se trata de prejuízos que por natureza não comportam compensação. Tem de ser acrescida a culpa não insignificante. Praticamente induvidosa nesta correlação é a influência que exerce a função de satisfação sobre o dinheiro da dor nos casos de ofensa ao direito de personalidade. ${ }^{136}$ Isso, contudo, também ocorre quando as ofensas são tão intensas que aniquilam na vítima toda capacidade mental e também suas

percepções sensoriais. Diante de tais situações, a função de compensação recua totalmente, por não mais ser possível uma qualquer espécie de compensação. Nesses casos, se preciso for, a prestação do dinheiro da dor pode basear-se tão somente na função de satisfação. ${ }^{137} \mathrm{O}$ mesmo vale, correspondentemente, para danos diminutos, o que, em todo o caso, não é reconhecido por uma parte da jurisprudência, por não ser compensável. ${ }^{138} \mathrm{Um}$ dinheiro da dor apoiado, única ou preponderantemente, na função de satisfação pode, pois, dado o caso, ser concedido. ${ }^{139}$

Com isso, também o último argumen to contra a função penal do dinheiro da dor mostra-se inexitoso.

\section{Conseqüências}

O conceito de satisfação tornou-se sinônimo de pena privada, ${ }^{140}$ a ser considerada inteiramente como matéria de direito civil. $\mathrm{O}$ acentuado relevo dado ao elemento penal no dinheiro da dor não poderia ficar sem conseqüências na sua evolução.

135. Cf. anterior p. 260; mas também OLG Frankfurt, VersR 1983, 545. OLG Frankfurt, VersR 1983, 545

136. Cf. sobre isto Schwerdtner, em: MünchKomm, Vol. 1, 2. ed. 1984, §12 Num. marg. 163 e sgs., 291 e sgs, 296.

137. BGH, JZ 1976, 559 = NJW 1976, 1147; Schwerdtner, Persőnlichkeitsrecht, p. 281; critico sobre isto Schiemann, pp. 15 e sg;; BGH, NJW 1981, 1613; NJW 1982, 2123. Isto vale também para a sentença do BGH, VersR 1967, 495, mas que trata de uma outra constelaçáo, uma ampliaçăo de operaçăo. Como a sentença está fundamentada, há a presunçao de que $\mathrm{O} B G \mathrm{H}$ está de acordo com a doutrina segundo a qual a violaçăo do dever de esclarecer é uma violaçăo da personalidade e não uma lesão física. (ć. sobre isto B.-R. Kern/Laufs, Die ärztliche Aufkärungspflicht unter besonderer Berücksichtigung der richterlichen Spruchpraxis, 1983, pp. 149 e sg., com mais indicaçōes). Porém o BGH ficou neste caso vinculado à cognição da instância anterior. Por isso e por que a sentença ficou sem conseqüências na jurisprudência (OLG München, MedR 1989, 40 e sgs, por ex., não aproveitou desta idéia), esta indicação não precisa ser levada em conta. (mas cf. sobre isto Schiemann, pp. 12 esg.)

138. O KG porém, funda isto na sua decisão (DAR 1974, 297, 298) não na falta de necessidade de compensação, mas no argumento de que uma satisfação não seria oferecida.

139. Assim por ex., OLG Düsseldort, MedR 1985, 85, "quando o doente foi sujeitado a uma cirurgia, que foi realizada impropriamente. As conseqüências permanentes prejudiciais porém, foram evitadas por uma [outra] cirurgia necessária [além da primeira cirurgia] e realizada por um outro médico." O [primeiro] médico realizou uma cirurgia raramente praticada, que uma clínica especia deveria fazer, e violou assim a sua diligência medicinal.

140. Apenas um pouco mais moderado Herm. Lange, p. 12 ("pelo menos na área de transiçăo).
Quem acolhe a pena privada como princípio básico da satisfação perguntará se ela efetivamente se apresenta com função de compensação em todos os casos ou apenas numa área central delimitada por STOLL: A satisfação "interessa na prisão por dívida do direito civil quando a ofensa ao sentimento jurídico da vítima é mais importante que o prejuízo ocasionado, e isso pertence à esfera privada em tal medida que não comporta tratamento penal; ou, então, a punição no direito penal seria desmedida". ${ }^{141}$ Tal importa dizer que num grande número de casos normais ${ }^{142}$ o dinheiro da dor seria determinado unicamente pela função de compensação. ${ }^{143}$

Isso pressupõe renúncia ao dogma da inseparabilidade dos elementos constitutivos do dinheiro da dor, o que na prática judicial não raras vezes acontece ${ }^{144}$ sem que sejam tiradas as necessárias conseqüências. $O$ dinheiro da dor deveria ser identificado separadamente em suas funções de compensação e de satisfação. Isso facilitaria a discussão racional dos fatores de cálculo a serem respectivamente considerados. ${ }^{145} \mathrm{O}$ dinheiro da dor, como inde-

141. H. Stoll, parecer, pp. 152 e sg.

142. Cf. sobre isto anteriormente, anotaçōes 128-131.

143. Assim também já Pecher, Der Anspruch auf Genugtuung als Vermögenswert, em: AcP 171 (1971), 44-81, 71.

144. Köndgen, Haftpflichtfunktionen und Immaterialschaden am Beispiel von Schmerzensgeld bei Gefährdungshaftung, 1976, p. 76, fala neste contexto com razão de uma "protestatio facto contraria"e documenta a sua opiniāo com algumas citaç̄es excelentes da jurisprudência. Da jurisprudência mais recente, cf. por. ex. LG Trier, VersR 1983, 791: uma indenização em dinheiro da dor necessária a uma compensação, para realizar a funçắo de satisfaçăa."

145. Pecher, Anspruch, 79; parecido também Esser/Weyers, p. 528.

146. E. Lorenz, pp. 125, 174.

147. Cf. sobre isto Herm. Lange, p. 439: "As tabelas existentes sobre a indenização em dinheiro da dor são considerados na prática pela grande grande maioria como ajuda importante de orientação, mas elas não podem substituir um exame de todas as circunstâncias relevantes."

148. Mais extensamente do que a situação legal atual. Cf. sobre isto também Pecher, Anspruch, 76 com mais indicações.

149. Assim também Pecher, 76; ć. sobre isto também Herm. Lange, p. 436 anotaçăo 63. 
jurídica, porque o estado atual - que não permite seguro de responsabilidade por satisfação, mas na falta de separação das funções o seguro tem de incidir em toda a sua plenitude ${ }^{150}$ - frustra a idéia de satisfação.

Com a possibilidade de seguro da pena privada, cai simultaneamente uma das principais objeções à jurisprudência do $\mathrm{BGH}$, 151 alicerçada em "uma requintada idéia de expiação não necessariamente penal", para os casos de perda total da capacidade mental e da percepção sensorial. A jurisprudência, que hoje se vê exposta a uma justa censura, por assegurar aos parentes próximos, contrariamente à proibição ao art. 253, um direito próprio ao dinheiro da dor, obteria então um fundamento intrínseco, cujas falhas ela hoje mal pode ocultar.

A inequívoca relevância do caráter de pena privada pode também contribuir com algo para a solução do problema de saber se cabe pagar dinheiro da dor nos casos de ofensa ao direito individual comum de associação (allgemeine Verbandspersönlichkeitsrechts). ${ }^{152}$ Como a pena privada propicia um sentimento de satisfação não somente à pessoa atingida, ${ }_{1}^{153}$ dado que opera também sobre o agente, é de, como resultado final, responder com um

sim à pena privada. Seria de considerar, nesses casos, a exclusão da herdabilidade passiva. Inversamente, isso também é válido nas pretensões de dinheiro da dor contra o Es. tado, quando só servem à satisfação da pessoa atingida. ${ }^{154}$

Além disso, a satisfação não deve ser concedida nos casos de responsabilidade delitual sem culpa (arts. 829 e 833). ${ }^{155}$ Isso, de lege ferenda abre a possibilidade de admitir o dinheiro da dor em função de compensação também nos casos de responsabilidade objetiva. ${ }^{156}$ Ao demais, a concessão da satisfação pressupõe prova positiva de culpa. Não bastam, para tal, meras decisões sobre ônus da prova; bastam, porém, para o dinheiro da dor em função de compensação. São também de considerar os diferentes critérios de imprudência no direito penal e no direito civil; para que alguém fique obrigado a indenizar, basta um comportamento objetivo contrário a dever, mas a pena privada, ao contrario, exige o pressuposto da censurabilidade individual. ${ }^{157}$ Por último, o dinheiro da dor, na função de satisfação, diversamente do que ocorre na função de compensação, não poderia ser outorgado como renda. Isso seria contrário ao seu caráter de pena privada. ${ }^{158}$

150. Herm. Lange, p. 436, anotação 63.

151. BGH JZ 1976, 559, 560.

152. Sobre a situação da discussăo cf. Klippel, Der zivilrechtliche Persönlichkeitsschutz von Verbānden, em: JZ 1988, 625-635, 634 e sg.

153. Com razáo constata Klippel, 635, neste ponto: "Como uma pessoa jurídica pode sentir satisfaçăo, fica incompreensível."

154. LG Hamburg, NVwZ 1987, 833, sobre a assim chamada "caldeira hamburguesa".

155. Cf. sobre isto Herm. Lange. pp. 433 e sg.

156. Cf. sobre isto Köndgen, p. 138; Herm. Lange, p. 426 ( com dúvida); e E. Lorenz, p. 226.

157. Assim também Köndgen, p. 122.

158. Pecher, 76: "A idéia de um regular e repetido apaziguamento do sentimento de justiça é errónea."

Revista da Faculdade de Direito da UFRGS, v. 17, 1999
A nítida separação das duas funções evidencia que todos os discutidos fatores de estimação ${ }^{159}$ da função de satisfação têm de ser ordenados, e só levados em conta na correspondente medida. Dificuldades que possam surgir, como, por exemplo, relativamente à significação da capacidade patrimonial do ofensor, ${ }^{160}$ resolvem-se ao tornar-se claro que isso só tem relevância na satisfação. ${ }^{161}$ Aqui, o levar em conta explica-se sem constrangimentos, a partir do pensamento de que também o sistema alemão de índices do dinheiro da dor fundamenta-se no direito penal.

Conseqüências igualmente surgem no tocante à questão do desconto de penas criminais no dinheiro da dor, e vice versa. ${ }^{162}$ Contra semelhante dedução foi oportunamente objetado que ele é dificilmente exequível, que a pessoa atingida deve sofrer uma retirada ( $A b z u g$ ) no seu dinheiro da dor tão-somente porque foi dispensada de uma sentença penal. Essa objeção, todavia, repousa na idéia de um montante unitário do dinheiro da dor e despreza a diversidade de funções. Não se trata - mesmo de acordo com a jurisprudência hoje

praticada - de podar o dinheiro da dor onde ele invade a compensação, mas de determinar o excesso da função de satisfação em sua correta extensão. A judicatura, quanto a isso, desconta penas criminais em diversas extensões. Alguns julgados deixam de lado, inteiramente, a função de satisfação, ${ }^{163}$ enquanto outros pura e simplesmente a restringem em diferentes porções. ${ }^{164}$

A pena privada se diferencia da pena criminal nisto que esta serve em primeiro lugar à satisfação da comunidade jurídica, enquanto que aquela à da vítima. ${ }^{165}$ Isso ainda é confirmado na circunstância de que a pena criminal, enquanto pena pecuniária, deve ser paga ao Estado ou a um terceiro, ao passo que a pena privada vai para a vítima. A pena criminal pode ser influenciada por fatores que são totalmente irrelevantes para a pena privada, como, por exemplo, a ressocialização como finalidade da pena. ${ }^{166}$ Mas também é de levar em conta, em certos casos, a circunstância de que em uma sentença penal vários atos delituosos são punidos com uma só pena conjunta. ${ }^{167}$ Essa pena global serve, essencialmente, para a expiação de um outro fato delituoso con-

159. Cf. anteriormente, anotaçōes 14, 18-23.

160. Por ex., Esser/Weyers, p. 527: "Atrás da jurisprudência pode haver parcialmente idéias de satisfação" (Acentuação pelo autor). 161. Isto vale também para a jurisprudência atual, que muitas vezes não se dá contà disto.

162. AG Flensburg, MDR 1973, 948. Cf. também BGH, NJW 1988, 2749.

163. OLG Düsseldorf, NJW 1974, 1289.

164. OLG Stuttgart, VersR 1989, 1150,1151: "A função de satisfação da indenização pedida em dinheiro da dor é neste caso diminuida. OLG Düsseldort, VersR 1989, 1203: "A necessidade da vítima ter uma certa satisfação pela injustiça não deixa de existir pelo fato... "LG Köln, VersR 1990, 1129, 1131: " "... de que só pode ter pouca importância para a fixação da indenizaçăo em dinheiro por danos morais."

165.LG Stuttgart, NJW 1978, 595; LG Flensburg, VersR 1988,740.

166. OLG Hamm, MDR 1974, 1018: "Além disso, a tentativa de ressocializar o réu evidentemente não pode ser à custa da vítima do crime."

167. LG Köln, VersR 1990, 1129, 1131 
juntamente julgado, de modo que não entra na estimação do dinheiro da dor. Essas reflexões mostram que, em todo o caso, ambas as funções não são sempre incondicionalmente compensadas uma com a outra. Com isso, todavia, ocorre que juridicamente sobressai, antes, o lado penal privado, ${ }^{168}$ o qual, também ai, forçosamente deixa aparecer uma pena privada, quando já suportou uma pena criminal, e vice versa. Especialmente nas ofensas que atingem a vítima no âmago da sua personalidade, ${ }^{169}$ como a desonra ou uma grave violação ao direito de personalidade, ${ }^{170}$ ocorrerá antes um apaziguamento da comunidade jurídica do que da vítima. Nesse ponto, geralmente se pensa de preferência numa redução da pena privada do que na sua total supressão. $O$ grau de redução, que inclusive pode chegar a zero, é por sua vez determinado conforme as circunstancias do fato. Em conseqüência, dificilmente uma pena privada recairá junto a uma pena cri- minal, senão que será mantida em diferente extensão.

\section{vI. Conclusão}

A pesquisa revela o entendimento da jurisprudência de que satisfação é pena privada. É discutível o motivo pelo qual ela nem sempre expressa isso claramente, embora a sua formulação esteja tão próxima quanto possível da pena, sem no entanto empregar a palavra mesma. "Pois, que compensação de dano e satisfação ideal (...) assentam em distintos pensamentos jurídicos elementares, é coisa que afinal bem que deveria ser (outra vez) abertamente confessada". ${ }^{171}$ Se esse fundamento dogmático da satisfação for externado publicamente poderia ser ganho um espaço que permitiria pôr em evidência, claramente, o princípio da pena privada, bem como, ao mesmo tempo, delimitá-la em sua aplicação. Evitar-se-iam assim falhas supérfluas de fundamentação.

168. Apoiando-se no que sobressai no plano do direito profissional, que pode fazer necessária no direito médico uma condenação no plano do direito profissional ao lado de uma pena criminal.

169. OLG Hamm, MDR 1974, 1018; LG Stuttgart, NJW 1978, 595; e LG Flensburg, VersR 1988, 740; Precário porém, OLG Düsseldorf, NJW 1974, 1289.

170. Por isso a decisão do OLG Koblenz, VersR 1990, 165, 166 é duvidosa. O tribunal deixa passar a função de satisfação para o segundo plano em um caso em que uma mulher foi descrita em um anúncio de jornal como prostituta.

171. Pecher, AcP 185, 387.

\section{Problemas Atuais da Livre Apreciação da Prova}

\author{
Carlas EAllerto ethrana de Olineina
}

Professor da Faculdade de Direito da UFRGS, Doutor em Direito pela USP. Desembargador do Tribunal de Justiça do RS.

\section{Introdução}

\section{SUMÁRIO}

1. Introdução;

2. Alguns problemas atuais da livre apreciação da prova;

3. O controle da liberdade concedida ao órgão judicial nessa matéria;

Bibliografia. tema da livre apreciação da prova ${ }^{1}$ tem merecido ao longo da história regulação mais ou menos rigorosa, na medida em que se busque restringir ou ampliar a liberdade do órgão judicial no exame do material fático recolhido no processo. O rumo tomado, convém ressaltar, encontra-se quase sempre sintonizado com a confiança depositada no júiz e os valores imperantes na época.

Embora não constitua objeto deste trabalho a reconstituição do fio histórico do problema, deve ser sublinhado que, bem ou mal, apesar das naturais marchas e contramarchas, a linha mestra de desenvol. vimento da relação do juiz com a prova, e principalmente dos poderes deste na sua

1. COSTA, Lopes da. Direito Processual Civil Brasileiro. Rio de Janeiro: Forense, 1959, 2. ed., tomo III, $n^{2} 240$, p. 240 , critica acertadamente a impropriedade da expressão "livre convicçáa", recomendando em seu lugar "livre apreciação da prova", pois a contraposição entre conviç̧ão livre e convição forçada espelha um contra-senso. Força é convir, porém, que convicção livre do juiz só poderá existir se houver livre apreciaçăo da prova. 